\title{
What's the Future of Doctors in China?
}

\author{
Jingmin Cheng ${ }^{1}$, Tengfei $\operatorname{Tan}^{1}$ \\ ${ }^{1}$ School of Management, Shanxi Medical University, PO Box 605, No. 56 Xinjian South Road, Yingze District, Taiyuan, \\ Shanxi, China \\ Correspondence: Tengfei Tan, School of Management, Shanxi Medical University, PO Box 605, No. 56 Xinjian South \\ Road, Taiyuan, Shanxi, China.
}

\author{
Received: September 17, 2015 Accepted: October 9, 2015 Online Published: October 17, 2015 \\ doi:10.11114/smc.v3i2.1151 \\ URL: http://dx.doi.org/10.11114/smc.v3i2.1151
}

\begin{abstract}
China's doctors are in crisis and in danger, they are under threat of their personal safety at work. Since its birth in 1949, the People's Republic of China has undertaken a series of remarkable health system experiments for many years. Despite the remarkable increase in the hospitals in China, the policymakers often overlook the unfilled medical jobs and medical education. Most doctors in China are overworked and underpaid. We urge the policy makers to protect doctor's right, make a long-term health policy, and build a health system with safety, high-quality and sustainability.
\end{abstract}

Keywords: China, health policy, doctors, doctor-patient relationship, pressure

\section{Introduction}

China's doctors are in crisis and in danger, they are under threat of their personal safety at work (Lancet, 2012). The annual average number of assaults on doctors per hospital increased from 20.6 assaults in 2008 to 27.3 in 2012, according to a sample survey released by the Chinese Hospital Association (CHA) on August 15, 2013, the survey was conducted among staff and patients at 316 hospitals nation-wide from December 2012 to July 2013 (China Daily, 2013).

Facing the deterioration doctor-patient relationship and to rebuild the image of doctors tarnished by various corruption scandal and restrain their behavior, the government established the circular. The National Health and Family Planning Commission released a circular on Feb. 20 that bans doctors of second-class public hospitals and above from taking "Red envelopes" or gift money from patients starting from May 1, 2014. But, it can just works for a short time or may be dose not work, moreover, it does not touch the deeper reason. Does this policy really solve the problem? The answer is no, because it does not catch the roots of the deterioration of doctor-patient relationships, which are systemic and interlocking. There are many possible reasons why Chinese doctors are under threat, poor investment in training and paying doctors is an important factor among them, which could lead to medical errors, corruption, and poor communication between health professionals and patients (Lancet, 2012).

\section{Discussion}

With the rapid development of economy and the dramatic improvement of living standard, China has undergone rapid epidemiological changes in the past few decades, including striking declines in fertility and child mortality and increases in life expectancy at birth (Gonghuan et al., 2013). The shift to non-communicable diseases (NCDs), known as the epidemiological transition has now arrived in China (Yuanli et al., 2013). The demographic transition has been driven by decades of low fertility and rising longevity; more than $30 \%$ of China's population will be older than 60 years, and many people older than 80 years by 2050 (Yuanli et al., 2013). The current situation of China poses great challenge and pressure to the government in its health care and social service system.

A functioning health care system is fundamental to the achievement of universal coverage for health care, which has been the focus of statements in recent years by advocacy groups and other organizations around the globe (Anne, 2014). Since its birth in 1949, the People's Republic of China has undertaken a series of remarkable health system experiments for many years (David \& William, 2015). The progression is remarkable for such a country whose population is large and resource is limited. With the increasing investment on health, especially for the medical facilities and hospitals, there is a dramatic increase in the number of hospitals, including general hospitals, hospitals specialized in traditional Chinese medicine, and specialized hospitals, in China form 19712 in 2008 to 24709 in 2013 (Figure 1). 


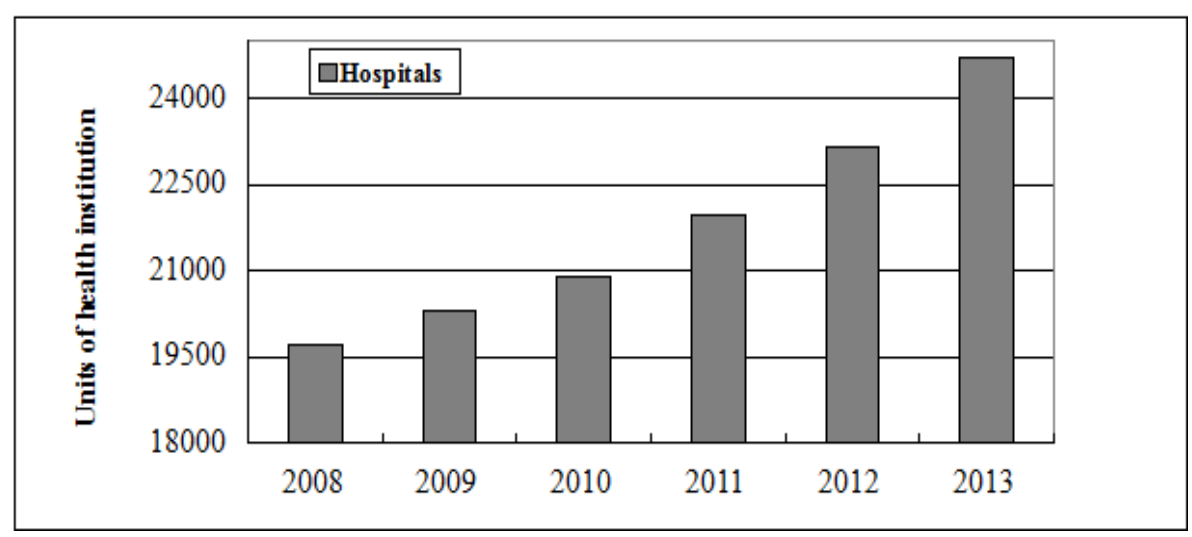

Figure 1. The number of hospitals in China

Source: http://www.stats.gov.cn/tjsj/ndsj/2014/zk/html/Z2201e.htm

Despite the remarkable increase in the hospitals in China, the policymakers often overlook the unfilled medical jobs and medical education. From 2008 to 2013, the number of employed doctors in health institution in China has increased form 1791881 to 2285794 (Figure 2).

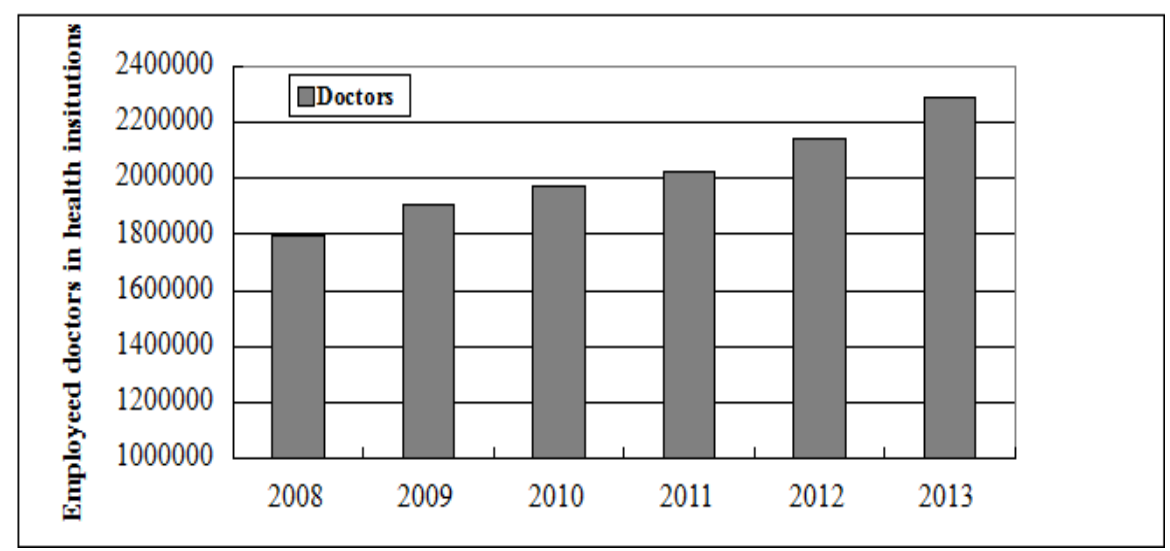

Figure 2. The number of employed doctors in China

Source: http://www.stats.gov.cn/tjsj/ndsj/2014/zk/html/Z2201e.htm

As the figures show, compared with the increase of hospitals in Figure 1, the increase rate of doctors in China is slower. In 2011, totally licensed doctors in health care institutions occupied $1.82 \%$ per 1000 persons, one doctor should diagnose and treat 6.9 patients and 2.4 beds averagely a day (National Bureau of Statistics of China, 2012).

Solid doctor-patient relationship forms one of the foundations of safe medical practice (Folkl, 2012). But In China, the doctor-patient relationship is in deterioration. For Chinese doctor, they are too busy to have a good communication with their patients. It is not uncommon for a specialist to see around 100 patients daily in the outpatient department. The time spent with each patient is very limited-usually less than 3 mins (Qi \& Peng, 2013). Some doctors involve themselves in corruptions, do not treat patients with dignity, or get poor professional quality. With the great development of health over the past 20 years, patients have raised their expectations ans demands and there is a growing number of complaints, and malpractice lawsuits (Moore et al., 2011). They held skepticism about doctors and their diagnosis, or complain about the necessary examinations and tests. In fact, despite of the currently advanced medical techniques, the cure for some diseases are still not available and the increasing complexity of modern medicine has exceed the ability of doctors to deliver care successfully (Broom, 2005).

The hospital environment requires doctors to be simultaneously good doctors, good team members, good learners and good employees (McDougall, 2013). However, the current situation of Chinese doctors make them burdened. Besides the great workload, the publication pressure of doctors in China makes the situation worse, since promotions are closely connected with — or even largely decided by - publications, which is a one-size-fits-all promotion system for all doctors applies from village clinics to tertiary referral hospitals, as well as the graduation, research grants, and payments (Lancet, 2015). The current promotion system makes the doctors in China could not pay their full attention to the common practice. What's more, the high bonus of article publication on Science Citation Index (SCI) journals leads to the doctors devote most of their time to write article and do experiments but not for the advances in medical technology and skills. 
As for doctors, $80 \%$ of them describe themselves as overworked and underpaid (Jingang, 2013). In a survey on Chinese doctors' annual average income done by Ding Xiang Yuan, the most popular bio-medical website in China with a registered user base of over 2 million, shows that from 2012 to 2013, one Chinese doctor's annual average income is around $¥ 67,516$ and $88.4 \%$ of the participants was not satisfied with their income (Ding Xiang Yuan, 2014).

\section{Conclusion}

Facing the deterioration doctor-patient relationship, the corruption in Chinese hospital is not the only urgent problem to solve. Doctors should not be the victim of the deepened contradictions of Chinese health system, otherwise no one will step into this high-risk profession, the health profession will be in a real crisis. We urge the policy makers to protect doctor's right, make a long-term health policy, and build a health system with safety, high-quality and sustainability. It is not only benefit China itself, it can also make a good example for the world.

We declare that we have no conflicts of interest.

Jingmin Cheng and Tengfei Tan are co-first authors.

\section{References}

Anne, M. (2014). Health Care Systems in Low- and Middle-Income Countries. The New England Journal of Medicine, 370(6), 552-557. http://dx.doi.org/10.1056/NEJMra1110897

Broom, A. (2005). Medical specialists' accounts of the impact of the Internet on the doctor/patient relationship. Health (London), 9(3), 319-338. http://dx.doi.org/10.1177/1363459305052903

China Daily. (2013) Violence against doctors on the rise: survey. http://usa.chinadaily.com.cn/china/2013-08/16/content_16897942.htm, accessed 2 Oct. 2015

David, B., \& William, H. (2015). Lessons from the East-China's Rapidly Evolving Health Care System. The New England Journal of Medicine, 372(14), 1281-1285. http://dx.doi.org/10.1056/NEJMp1410425

Ding, X. Y. (2015). The Study Report on Chinese doctors income form 2012 to 2013. http://vote.dxy.cn/report/dxy/id/64391

Folkl, A. (2012). The patient-physician relationship: classic questions and new directions. Virtual Mentor, 14(5), 365-367. http://dx.doi.org/10.1001/virtualmentor.2012.14.5.fred1-1205

Gonghuan, Y., Yu, W., Yixin, Z., George, F. G., Xiaofeng, L., Maigeng, Z., \& others. (2013). Rapid health transition in China, 1990 - 2010: findings from the Global Burden of Disease Study 2010. Lancet, 381(9882), 1987-2015. http://dx.doi.org/10.1016/S0140-6736(13)61097-1

Jingang, A. (2013). Which future for doctors in China? Lancet, 382(9896), 937. http://dx.doi.org/10.1016/S0140-6736(13)61928-5

Lancet. (2012). Ending violence against doctors in China. Lancet, 379(9828), 1764. http://dx.doi.org/10.1016/S0140-6736(12)60729-6

Lancet. (2015). China's medical research integrity questioned. Lancet, 385(9976), 1365. http://dx.doi.org/10.1016/S0140-6736(15)60700-0

McDougall, R. (2013). Understanding doctors' ethical challenges as role virtue conflicts. Bioethics, 27(1), 20-27. http://dx.doi.org/10.1111/j.1467-8519.2011.01893.x

Moore, P., Vargas, A., Núñez, S., \& Macchiavello, S. (2011). A study of hospital complaints and the role of the doctor-patient communication. Revista $m$ é dica de Chile, 139(7), 880-885. http://dx.doi.org/10.4067/S0034-98872011000700008

National Bureau of Statistics of China. (2012) China Statistical Yearbook 2012. http://www.stats.gov.cn/tjsj/ndsj/2012/indexeh.htm

Qi, L., \& Peng, X. (2013). Outpatient workload in China. Lancet, 81(9882), 1983-1984. http://dx.doi.org/10.1016/S0140-6736(13)61198-8

Yuanli, L., Gonghuan, Y., Yixin, Z., \& Richard, H. (2013). Policy dialogue on China's changing burden of disease. Lancet, 381(9882), 1961-1962. http://dx.doi.org/10.1016/S0140-6736(13)61031-4

\section{(cc) $\mathrm{EY}$}

This work is licensed under a Creative Commons Attribution 3.0 License. 